This is a pre-print of an article published in Waste and biomass valorization (Ed. Springer). The final authenticated version is available online at: https://doi.org/10.1007/s12649-018-0327-5 


\section{Optimization of down-stream for cellulases produced under solid-state}

2

3

4

5

6 Maria Marín, Adriana Artola, Antoni Sánchez*

7 Composting Research Group

8 Department of Chemical, Biological and Environmental Engineering

9 Universitat Autònoma de Barcelona

10 Edifici Q, Campus de Bellaterra, 08193-Cerdanyola del Vallès, Spain

11

12 *Corresponding author: Antoni Sánchez

13

14

15

16

17

18

\section{fermentation of coffee husk}


24 This work systematically studies the downstream process of the solid state fermentation 25 (SSF) of a mixture of coffee husk and wood chips, inoculated with compost, for cellulase production. Downstream of SSF (at pilot scale) remains as one of the less studied stages of the process, being critical in technical, environmental and economic terms. In this study, the specific downstream points considered were: i) enzyme extraction yield, in terms of extraction ratio solid:solvent, agitation mode and solvent type; ii) enzymatic activity recovery of the lyophilised extract and iii) efficiency of consecutive extractions. Results indicate a maximum activity recovery of $108 \pm 30 \%$ in the extraction performed at ratio 1:5 solid-solvent, in static mode and with distilled water. Statistical analysis revealed a high dispersion of the results and needs to be considered to extract consistent conclusions in any downstream of SSF. Lyophilisation demonstrated to be an adequate technology for enzymatic activity preservation. Regarding consecutive extractions, yield recovery in the first and second extraction maintain a similar value. In a framework of a zero-waste enzyme production process, different strategies have been tested for the remaining solid after extraction. Respirometric tests reveal that it is possible to aerobically stabilize the remaining solid obtaining a compost like material, whereas anaerobic digestion resulted in low methane yields $\left(51 \pm 3 \mathrm{~mL}\right.$ methane $\left.\mathrm{g}^{-1} \mathrm{VS}\right)$.

Keywords: Cellulase extraction, activity recovery, solid state fermentation, downstream, zero waste process. 
47 Nowadays, most of the studies carried on in the field of enzyme production through

48 solid state fermentation are focused on optimizing the production yield at a laboratory

49 scale. Extraction is mainly performed using a high ratio solid:solvent in the range of 1 to $15 \mathrm{~mL}$ per g, suitable for a laboratory scale but non-viable at an industrial one. The

51 present work differs from the others published so far as it focuses on the aspects related

52 to the downstream stage to be implemented at an industrial scale, like the optimization

53 of the extraction conditions in order to save resources, management of the remaining

54 solid after the extraction and conservation of the final product in low-cost mode.

55 The fact that the production process itself presents many advantages, as it has been

56 proved to be reproducible at a pilot scale, requires a low investment due to the use of a

57 residue as raw material, the equipment is simple and the production yield is high, makes

58 the whole process interesting for implementation at an industrial scale.

59 The scale of the experiments performed in this work allow to apply the results to the

60 design of an industrial plant for the production of low cost cellulase from coffee husk

61 and to its economic assessment, as well as the conservation of the cellulases by standard

62 ways. The remaining waste is also considered as a source of biogas or compost in a zero waste global strategy. 
Almost $85 \%$ of the energy consumed worldwide was obtained from fossil fuels during 2016 [1]. The excessive use of fossil fuels during the last years has produced an increment of $\mathrm{CO}_{2}$ level in the atmosphere, which is nowadays reaching an historical maximum of $409 \mathrm{ppm}$. This rise has a pernicious impact on the global climate creating a greenhouse effect and increasing temperatures around the globe. In the search for new renewable sources of energy, bioproducts like bioethanol are gaining relevance. However, its production process must be optimized in order to achieve a major use compared to fossil fuel. Among the different stages of bioethanol production, hydrolysis of the lignocellulosic material can be performed chemically, by an acid or alkaline reagent, or enzymatically using cellulases, which results in less harsh operational conditions, since most of the enzymes require mild operational conditions, avoiding great energy expenses and corrosion issues [2]. In fact, one of the main uses for cellulases is the conversion of cellulosic and lignocellulosic materials to bioethanol [3, 4]. For this reason, finding a low-cost and robust process for cellulase production is a key point in bioethanol manufacturing.

Cellulases have been in the market for more than 30 years, and they are used in all type of industries. As an example, cellulases have a role in textile industry as biopolishers of fibres or in the pulp and paper field in enzymatic deinking and to improve brightness of the product. Microbial production is the most used method in industry for cellulase production. A wide variety of microorganism like fungi [5], yeast or gram-positive [6] and gram-negative bacteria can be used in the production of cellulase. As a result, the morphology and specificity of the enzyme will depend on the 
Two main methods are used for cellulase production, submerged fermentation

$90(\mathrm{SmF})$ and solid state fermentation (SSF). Both methods show advantages and

disadvantages. No gradients of temperature and media composition are found in submerged fermentation. However, solid state fermentation requires smaller and cheaper equipment, which makes it economically attractive; besides, the option of using a lignocellulosic solid waste as a nutrient source and support for the growing of the microorganism increases the profit obtained in an industrial process and reduces the waste disposed into the environment. Several types of agro industrial wastes have been reported as sources of cellulose: Sun et al. [8] used banana peel obtaining a cellulase activity filter paper unit (FPU) of 5.56 FPU per gram of dry matter; Dhillon et al. [9] also reported a cellulase production of $133.68 \mathrm{U}$ per gram of dry substrate from apple pomace using Aspergillus niger NRRL-567 as inoculum. Other residues used as substrate are wheat straw, corn fibre or seaweed $[10,11]$. The mentioned cases were all reported at laboratory scale. Few processes have been developed at a scale large enough to be used for industrial purposes, especially when considering all the downstream process. Cerda et al. [12] reported a cellulase production of 9 FPU of enzyme activity per gram of dry matter from coffee husk, a residue obtained after the thermal peeling of the coffee bean. In that case, solid state fermentation was carried on under non-sterile conditions and no temperature control at a $4.5 \mathrm{~L}$ scale, allowing the consortia of microorganisms present in the residue to develop. Maximum production was observed after 48 hours of process. Also, Cerda et al. [12] developed a strategy to obtain a continuous stable production of cellulase from the mentioned residue. This process was tested at pilot scale, obtaining higher temperatures, which caused a decrease in the production, but showing that this strategy was valid for scaling up. These results confirmed coffee husk as a promising low-cost source of cellulase, as it cannot be used 
as animal feedstock, according to local regulation, and the only possible use would be composting, less profitable than enzyme production.

117 of the final product from the solid matrix. In this specific case there is no information 118 regarding recommended extraction agent, ratio solid:liquid for the extraction or agitation method. The optimization of these parameters is not a key point at laboratory scale but at industrial scale will determine the profitability of the process. Also, after the extraction, the solid waste remains, which still can be used in a more profitable way than landfilling. Thus, considering these facts, the current work aims to study different aspects of the downstream process for the production of cellulase from coffee husk, including optimal extraction conditions, taking into account different extraction agents, agitation methods and solid:liquid ratios. Also, the dispose of the solid residue after extraction has been studied, considering its use as feedstock for anaerobic digestion and

\section{Materials and methods}

\section{Raw material}

Coffee husk was provided by Marcilla S.A (Mollet del Vallés, Barcelona, Spain). physico-chemical characteristics of this waste are summarized in Table 1 . The residue was collected within $24 \mathrm{~h}$ after its production and stored at $-20{ }^{\circ} \mathrm{C}$ until needed. During SSF, coffee husk was mixed in a proportion 9:1 (w:w) with compost provided by the waste biological treatment plant of the Consorci per a la Gestió dels Residus del Vallès 
138 Oriental (Granollers, Barcelona, Spain). Compost was added to increase the initial microbial population.

The mixture of compost and coffee husk was mixed with wood chips as bulking agent to provide an adequate porosity to the final mixture $(\mathrm{CH})$. Wood chips were obtained from Trabede Jorba composting plant (Jorba, Barcelona, Spain), and mixed in a ratio 1:1 (v:v). Moistening of the mixture was not necessary since its value was always near $60 \%$ in weight. The suitability of this industrial residue as raw material for cellulase production through SSF has been described for the first time by Cerda et al. [12], where details of the process and cellulase production range are thoroughly provided.

\section{SSF Materials and experimental set up}

SSF was carried out in 4.5 and $10 \mathrm{~L}$ (working volume) adiabatic reactors, as described in detail in previous works $[13,14]$. Both types of reactors were identical in operation. Briefly, air flow was adjusted by an air flow controller (Bronkhorst Hitec, The Netherlands), provided to the bottom of the reactor and evenly distributed by a net placed below the biomass. The oxygen content of output gases was measured by an electrochemical O2-A2 oxygen sensor (Alphasense, United Kingdom) and data were collected using a personal computer HP Compaq LA1951g Intel core ISvpro (HewlettPackard, USA), equipped with Ubuntu operation system. Data analysis was carried on by a non-commercial tailor-made software. Temperature was also measured (Transmisor CCPI/T-120, Seneca, Italy). Air flow was supplied to the reactors assuring that oxygen was always above $10 \%$ in output gases through a feedback control system in which two oxygen content set points were fixed: $11.5 \%$ as a minimum and $12.5 \%$ as maximum. Two values of air flow are set by the user, when oxygen concentration is 
lower than $11.5 \%$, the system selects the maximum air flow, when oxygen content is higher than $12.5 \%$, the system selects the minimum air flow. Reactors capacity (mass of mixture coffee husk, compost and bulking agent) was $2.7 \mathrm{~kg}$ for $10 \mathrm{~L}$ reactors and 1.5 $\mathrm{kg}$ for $4.5 \mathrm{~L}$ reactors.

\section{Cellulase activity recovery - Downstream}

\section{Cellulase activity determination - Reference value}

To obtain the total cellulase activity, an extraction in agitated mode at 1:15 solid: solvent ratio and buffer citrate mono hydrated $0.05 \mathrm{M}$ solution at $\mathrm{pH} 4.8(\mathrm{BC})$ as solvent was performed during half an hour. Pirota et al. [15] performed different experiments for cellulase extraction using ratios of 1:3, 1:6 and 1:9 finding that 1:9 was the optimal extraction ratio. Also Chandra et al. [16] found an optimum extraction ratio for $\beta$ endoglucanase at 1:4 ratio w:v from fermented wheat bran. In the case of coffee husk we have observed that an extraction ratio of 1:15 w:v guarantees a good contact between solid and liquid to ensure a total extraction of the enzyme [12].

Activity recovery was calculated referring the activity obtained in the extraction at given conditions as a percentage of the activity in the standard extraction, performed at 1:15 ratio, using $\mathrm{BC}$ and orbital agitation, according to equation 1.

$$
100 \times \text { Cellulase activity }\left(\mathrm{U} \mathrm{g}^{-1} \mathrm{DM}\right)
$$

$$
\% \text { Activity recovery }=
$$

Standard Cellulase activity $\left(\mathrm{U} \mathrm{g}^{-1} \mathrm{DM}\right)$

Since various replicates of extractions under same experimental conditions (6 or 5 depending on the case) were performed, the rule of $25 \%$ was applied, discarding the values that differ more than $25 \%$ from the average. 
Extractions were performed to evaluate the recovery of cellulase activity under different experimental conditions. The experimental parameters assayed were solvent type, extraction mode and w:v solid:solvent (w:v) ratio. The variations of each parameter were:

a) Solvent type: Two different solvents were used to perform extractions, distilled water (DW) and BC.

b) Extraction mode: The extraction modes were three: 1) no agitation (static mode), ii) orbital agitation at $120 \mathrm{rpm}$, and iii) circulation of the solvent through a column packed with the waste at $140 \mathrm{~mL} \mathrm{~min}^{-1}\left(8.4 \mathrm{~kg} \mathrm{~h}^{-1}\right)$, which resulted in the renewal of the whole volume of liquid 7 times during the extraction time.

c) Waste to solvent ratio (weight:volume): Assayed ratios of solid:solvent were 1:2, $1: 3$ and $1: 5$.

The different combinations of these tested variables are shown in Table 2.

Between 150 and $200 \mathrm{~g}$ of solid from SSF after $48 \mathrm{~h}$ of fermentation were used in every extraction. The solid and the solvent were in contact during half an hour under the different regimes stated above and then the liquid phase decanted and centrifuged during 10 minutes at $10000 \mathrm{rpm}$. Cellulase activity of the supernatant was measured and referred to the value considered the total cellulase activity produced.

Experimental set up for static and agitated mode extraction consist of a set of plastic containers of equal dimension and shape where solvent and solid were placed. Static extraction was performed placing the fermented solid and the chosen volume of solvent in the plastic container and waiting for half an hour. To obtain the extracted liquid in agitated mode, the same procedure was followed but plastic containers were 
212 placed in a Sanyo orbital shaker IOC402.XX1.C (Sanyo UK) incubator for half an hour 213 at $120 \mathrm{rpm}$ and room temperature.

214 The experimental set up used in liquid recirculation extraction was composed of 215 a peristaltic pump Watson-Marlow 403U/L2 Ultra compact twin channel pump with 216 variable rotor speed from 0 to $99.9 \mathrm{rpm}$ (Watson-Marlow Alitea, England) and a $2 \mathrm{~L}$ 217 plastic vessel with two adaptors, one at the top and one at the bottom, connected by 218 plastic tubes to the pump input and output. Inside the vessel, a device was coupled to let 219 the water fall over the biomass in a drop-shower mode, in order to achieve a 220 homogenous contact with the solid in a percolation mode. Fermented material was 221 placed inside the vessel and each solvent added. The flowrate was set up in the pump 222 and liquid circulation lasted for half an hour.

\section{Number of extraction stages}

225 Enzyme recovery from consecutive extraction stages was assayed performing three 226 consecutive extractions to the same fermented material. Between extractions, the 227 biomass was drained to reduce its moisture as much as possible. 1:2 solid:solvent (w:v ratio) was chosen for these experiments. Extractions were performed using the lowestcost agitation mode and extraction solvent, which are static mode and DW as solvent, respectively, in order to evaluate if this strategy implied an increase in activity recovery

231 with no extra cost.

\section{Lyophilisation}

234 Supernatant from extractions at 1:2 and 1:5 solid:solvent ratios, in static mode and using 235 $\mathrm{BC}$ as extraction agent were used in this experiment. According to Farinas et al. [17] 


\section{$254 \quad$ Zero waste strategies}

\section{Biomethane Potential (BMP)}

256 Biomass fermented for the production of cellulase was tested after extraction as 257 feedstock for biogas production through anaerobic digestion. Anaerobically digested

optimum cellulase $\mathrm{pH}$ regarding stability is between 4 and 5.5, so $\mathrm{BC}$ was selected to preserve the enzyme stability.

Samples of $10 \mathrm{ml}$ of the supernatant obtained from the centrifuged extract were frozen at $-80^{\circ} \mathrm{C}$ inside plastic falcons and stored at same temperature. On the other hand, $500 \mathrm{~mL}$ of same supernatant were frozen at $-80^{\circ} \mathrm{C}$ into two $250 \mathrm{~mL}$ beakers and lyophilized using a Virtis 5L sentry lyophilizer 248627 (Virtis, Gardiner, USA) connected to an Edwards vacuum pump RV5 A653_01_903 (Edward, United Kingdom). The beakers used in the experiment were weighted before and after the removal of the powder and the dry cleaning of the beaker. The obtained powder was easily removed from the walls of the flasks so there were no perceptible losses. After that, the remaining powder was mixed and pulverized using a ceramic mortar in order to completely homogenize the solid. Mass of powder obtained from the $500 \mathrm{~mL}$ extract was calculated by weigh difference, and the equivalent quantity to $10 \mathrm{~mL}$ of original supernatant was dissolved in DW. The remaining powder was stored at $4{ }^{\circ} \mathrm{C}$.

Cellulase activity for the redisolved solid and for an unfrozen sample of $10 \mathrm{~mL}$ was measured for comparison using filter paper units (FPU) of activity for the supernatant obtained after extraction for both $1: 2$ and 1:5 ratios. sludge from a municipal WWTP in Sabadell (Barcelona) was used as inoculum. 
German Institute for Standardization and reported by the Ordinance on environmentally compatible storage of waste from human settlements [18], detailed by Ponsá et al. [19].

According to this standard methodology, BMP tests were carried out under mesophilic conditions and during approximately 20-30 days. Inoculum and biomass from SSF were mixed in a feed to inoculum (F:I) final ratio of 0.5 and placed in hermetic closed bottles. Each sample was tested in triplicate. The ratio F:I was calculated based on substrate and inoculum initial amounts of volatile solids (VS). According to Ponsá et al. [19], this ratio is the optimum to maximize biogas production. The content of volatile solids in fermented $\mathrm{CH}$ and anaerobic inoculum were measured, obtaining a percentage of $29.8 \%$ and $1.1 \%$ on a wet basis, respectively. A triplicate with only inoculum was also tested as control and its biogas production subtracted from the sample tests.

All the bottles were placed in an incubator Memmert In750 (Memmert, Germany) working at $37^{\circ} \mathrm{C}$ for $21-25$ days. The amount of biogas produced was calculated from the biogas pressure, measured by an ISE 30A-01-P vacuum switch (SMCpneumatics.com, USA), temperature and headspace volume. The bottles were manually agitated before and after measurement, and biogas was periodically released to avoid overpressure.

Representative measures of methane percentage in the biogas were taken at different days of incubation. Percentages of methane and carbon dioxide in the biogas were measured using a gas chromatograph 5890A with a column 17066_F ParcpackQ (250C), support 100/120, tube 3m 1/8”x $5.5 \mathrm{~mm}$. Initial oven temperature was $70^{\circ} \mathrm{C}$, final oven temperature was $120^{\circ} \mathrm{C}$, determination time was 8 min, injector temperature was $150^{\circ} \mathrm{C}$ and detector temperature was $180^{\circ} \mathrm{C}$. Methane peak was detected at 0.8 minutes. $100 \mu \mathrm{l}$ of gas sample were required for the analysis. 


\section{Composting assays}

286

287

Solid material after SSF and cellulase extraction was stabilized in order to test its suitability as soil organic amendment. Experiments were carried out in 10 L working volume reactors. Reactors have been previously described [13, 20]. The composting process was performed with air supplied under OUR control [14], which ensures maximum $\mathrm{O}_{2}$ consumption during the experiment.

\section{Analytical methods}

\section{Cellulase activity determination}

Cellulase activity was measured using filter paper analysis as described by Ghose [21]. The extract was centrifuged $10 \mathrm{~min}$ at $10000 \mathrm{rpm}$ and the supernatant was analysed. An Activity Unit (U) or Filter paper unit (FPU) is defined as $1 \mu \mathrm{g}$ of glucose released in one hour under the assay conditions.

\section{Respirometric tests}

In this case, respirometric tests were performed on the residues before and after SSF in order to determine their stability (Ordinance on Environmentally Compatible Storage of Waste from Human Settlements and on Biological Waste-Treatment Facilities [18]). A dynamic respirometer constructed following the method described by Adani et al. [22] was used. The experimental device was described by Pognani et al. [23]. According to Gea et al. [24] the test was carried out at a constant temperature of $37^{\circ} \mathrm{C}$. All the experiments were performed in triplicate. Cumulative oxygen demand at 4 days $\mathrm{AT}_{4}(\mathrm{~g}$ 
$\mathrm{O}_{2} \mathrm{~kg}^{-1}$ dry matter) and Dynamic Respirometric Index, DRI $24\left(\mathrm{~g} \mathrm{O}_{2} \mathrm{~kg}^{-1}\right.$ dry matter $\left.\mathrm{h}^{-1}\right)$, were calculated [24, 25].

OUR ( $\mathrm{g} \mathrm{O}_{2} \mathrm{~kg}^{-1}$ dry matter $\mathrm{h}^{-1}$ ) was calculated during solid state fermentation as a respirometric indicator of the biological activity of the mixture [14]. When obtaining $\mathrm{DRI}_{24}$, fermentations are carried on with temperature control at $37{ }^{\circ} \mathrm{C}$, while for OUR calculation, the fermentation is performed with no temperature control. OUR was expressed as the average value after an hour (OUR1h).

\section{Routine analytical methods}

$\mathrm{pH}$ was calculated by soaking $10 \mathrm{~g}$ of sample in $50 \mathrm{~mL}$ of distilled water. After $30 \mathrm{~min}$, pH value was measured with a $\mathrm{pH}$ meter Crison micro pH 2001. Volatile solids (VS), moisture content, total organic carbon (TOC), total Kjeldahl nitrogen, (TKN) and Soluble N-NH${ }_{4}^{+}$were measured according to TMECC [26].

TOC (Total Organic Carbon) was determined using an O.I. Analytical Solid TOC Analyser/Win TOC Solids v3.0, and TKN was measured using a Bloc Digester 6 (with six tubes capacity) (J.P. Selecta S.A., Barcelona, Spain) and a Büchi Distillation Unit K-355 (Flawil, CH). Fibre content (lignin, cellulose and hemicellulose) was determined by the method of Van Soest et al. [27]. Reducing sugars were determined using the method described by Miller et al. [28]. Air filled porosity was calculated using an air pycnometer, as described by Ruggieri et al. [29].

\section{Statistics}

t-student mean analysis comparison was performed to compare the mean values of activity recovery obtained under different experimental conditions. Also, three way 
331 ANOVA analysis was performed. Sigmaplot 11.0 (Systat software, Inc) was used for all 332 the calculations. Linear regression of the data using Microsoft Excel 2013 was also performed.

\section{Results and discussion}

\section{Waste characterization}

337 Table 1 shows the characterization of the waste. Moisture was adequate for solid state fermentation since it falls within the recommended values of $40-70 \%$. Krishna et al. [30] reported a range as wide as $20 \%$ to $70 \%$ for fungi growth and higher than $80 \%$ for bacteria, so no extra moistening was needed. Air filled porosity (AFP) was also adequate to ensure total aeration during the process. Ruggieri et al. [29] reported that the recommended AFP value is highly dependent on the material, and can vary from $30 \%$ to $60 \%$. Alburquerque et al. [31] found that due to the wide variety of methods for measuring AFP, the same measurement can vary between $26 \%$ and $61 \%$, so $77 \%$ obtained for coffee husk and bulking agent is acceptable. As the objective of the work was the production of cellulase, coffee husk fibres content was determined. According to literature, measured cellulose content in some lignocellulosic substrates for bioethanol production was within $32-47 \%, 34-45 \%$ and $42 \%$ for rice straw, wheat straw and corn straw [32], respectively, so the percentage of fibrous material present in coffee husk makes it suitable for cellulase production. As for the biodegradability of the residue, initial respirometric values on Table 3 show that the raw material is not stable and it can be aerobically degraded [18]. 
Figure 1 shows an example of the temperature and OUR1h profiles of a fermentation process performed in $10 \mathrm{~L}$ working volume reactors. At 48 hours roughly, according to

357 Cerda et al. [12], the maximum enzymatic activity was reached. Cerda et al. [12] also proved that maximum OUR1h and maximum cellulase activity were achieved simultaneously. Temperatures reached $70{ }^{\circ} \mathrm{C}$ in the thermophilic range. Maximum OUR1h achieved was $9 \mathrm{mg} \mathrm{O}_{2} \mathrm{~h}^{-1} \mathrm{~g}^{-1} \mathrm{DM}$. It was observed that the fermentation process is highly reproducible, as the differences in temperature profiles among all replicates were not higher than $6 \%$, presenting an average value of $98.7^{\circ} \mathrm{C}$ day (area below temperature curve). Oxygen consumption, on the other hand, presented a maximum deviation of almost $50 \%$ of the mean value, which was $1.5 \mathrm{mg} \mathrm{O}_{2} \mathrm{~h}^{-1} \mathrm{~g}^{-1}$ wet matter (WM). This parameter was calculated for each solid state fermentation process as total amount of oxygen consumed (mg) divided by process time (h) and initial quantity of wet matter inside the reactor $(\mathrm{g})$. Mean value of oxygen consumption was calculated as an average of the values obtained in the performed fermentations. Values of oxygen consumption seem to be related to the obtained cellulase activity extracted in standard conditions (1:15 ratio, $\mathrm{BC}$, agitated mode). The highest cellulase activity value was obtained in fermentation processes presenting the highest oxygen consumption, which were $1.3 \pm 0.2 \mathrm{FPU} \mathrm{g}^{-1} \mathrm{DM}$ corresponding to $2.3 \mathrm{mg} \mathrm{O}_{2} \mathrm{~h}^{-1} \mathrm{~g}^{-1} \mathrm{WM}$. Jimenez-Peñalver et al. [33] reported a correlation between sophorolipids production yield by Starmerella bombicola in winterization oil cake and oxygen consumption. Among the fermentations performed, a case was found where correlation between cellulase activity and oxygen consumption was not observed $\left(0.45 \pm 0.07 \mathrm{FPU} \mathrm{g}^{-1} \mathrm{DM}\right.$ corresponding to $1.7 \mathrm{mg} \mathrm{O}_{2} \mathrm{~h}^{-1}$

$\left.377 \mathrm{~g}^{-1} \mathrm{WM}\right)$. However, when extractions under different conditions using this fermented solid were performed and the cellulase activity was compared to the standard, the highest percentage of activity recovery was obtained, indicating that probably extraction 
at 1:15 (w:v) did not have the proper efficiency in this case. This can be due to the heterogeneity of the material and the size of the sample extracted as standard.

\section{Cellulase activity recovery - Downstream}

\section{Extraction method}

After 48 hours of fermentation the process was interrupted and different extraction strategies were performed on quantities of material between 160 and $200 \mathrm{~g}$, under different conditions. Table 2 shows the combination of the different extraction parameters and the activity recovery obtained, as well as the $\mathrm{pH}$ and conductivity of each extract. t-student test was performed comparing the means of the activity recovery values for each experimental condition. Results of the test are also presented in Table 2. As observed, the most favourable extraction mode, according to Table 2, was the one performed at 1:5 ratio in static mode using DW as extraction solvent with an activity recovery of $108 \pm 30 \%$. The less favourable conditions, according to Table 2 , are at a ratio 1:5 and DW as extractant but in agitated mode. As t-test showed, no differences due to extraction method can be appreciated between the means of 5-StaticDW, 5-Agitated-CB, 3-StaticDW, 3-Agitated-DW, 2-Static-DW and 5-Static-CB, being all equal to 5-Static-DW. This group of extraction methods that present higher activity recovery include the combinations in which DW and static agitation mode were used, which would be the most favourable conditions from an economic point of view. Linear regression carried out with the obtained results showed a very low correlation coefficient. Coefficients for each variable indicate that the most relevant extraction parameter is the extraction ratio, being 1:5 the most favourable one. On the other hand, solvent type is the less influencing parameter. This result agrees with that deduced from 
t-student test. According to these results, it is clear that solubility of the produced cellulase is not diminished by the difference in $\mathrm{pH}$ observed between $\mathrm{BC}$ extract and DW extract. On the contrary, higher $\mathrm{pH}$ seems to have a positive influence in the extraction yield. Rezaei et al. [34] reported buffer containing $50 \mathrm{mM}$ sodium acetate at pH 5 to have a positive effect on the recovery of commercial fungal-derived cellulase amended to switchgrass and a negative effect in the recovery of the same enzyme from solid state fermentation samples colonized by the bacterium Acidothermus cellulolyticus.

In the particular case of the extraction of cellulase from a solid matrix of fermented coffee husk it is clear that BC has no positive effect compared to DW extraction. Singh et al. [35] asserted that the ideal buffer would be selective and preferable of the same $\mathrm{pH}$ of the fermented substrate. As observed in Table 2, $\mathrm{pH}$ of the solid matrix, which corresponds to 5-Agitated-DW experiment, is very similar to the $\mathrm{pH}$ achieved in all extractions with $\mathrm{DW}$, where $\mathrm{pH}$ value depended only on the electrolytes from the solid matrix, contrarily to what happens with $\mathrm{BC}$ extract, which $\mathrm{pH}$ is close to 6 in all cases, due to the buffer effect of citrate. Comparing initial $\mathrm{pH}$ of $\mathrm{DW}$ and $\mathrm{BC}$, DW $\mathrm{pH}$ is closer to that value. Regarding this, Bera et al. [36] presented the extraction of amylase at different pHs ranging from 2 to 12 and observed no statistical significant differences among the results .

According to the data obtained, both agitated and static methods provide an adequate contact between solid and solvent. This can be due to the small size of the coffee husk particles, and consequently no aggregates were formed once in contact with the liquid. Singh et al. [35] reported no differences between static and agitated (220 $\mathrm{rpm}$ ) extraction modes for pectinase from bran, and only an increase of viscosity and colour in the extract. On the other hand, Shata et al. [37] reported a yield in milk- 
429 clotting (proteins) extraction from also bran of $3000 \mathrm{U} \mathrm{g}^{-1}$ in agitated extraction in front of $500 \mathrm{U} \mathrm{g}^{-1}$ in static extraction. Therefore, agitation requirements seem to be highly dependent on the type of enzyme. In the case of coffee husk and cellulase extraction, agitation mode has a low influence in the activity recovery yield.

Three independent extractions were performed in recirculated mode with DW as solvent and ratio 1:3 solid:liquid, with 7 times the recirculation of the whole volume of liquid. Also, another three independent extractions were performed using fermented coffee husk from the same process in agitated mode at same ratio and with DW as solvent. Activity recovery for both extraction modes was calculated, obtaining a $98 \pm 1$ $\%$ of activity recovery for the agitated mode and a $93.0 \pm 0.7 \%$ for the recirculated mode, showing that no improvement is achieved with recirculation.

\section{Number of extraction stages}

Three extractions in static mode, ratio 1:2 and DW as a solvent were performed and the cellulase activity compared to the standard in order to calculate activity recovery. Figure 2 shows cellulase activity recovery in those extractions. As it can be seen, although fermented material came from the same process, one of the replicates differs significantly from the others. One explanation could be the heterogeneity of the material, with an irregular distribution of the bulking agent. A decrease in the activity recovery through the different extraction stages is observed, but a total activity recovery after three extractions of $215 \%$ was observed in two of the replicates and a $144 \%$ for the remaining one. Activity recovery in the second extraction represents a percentage between $20 \%$ and $27 \%$ of the activity recovered in the first extraction. In the case of the second replicate. Pirota et al. [15] performed consecutive endoglucanase extractions over the same bran with DW reporting a $75 \%$ of recovery in the first extraction and 
almost a $25 \%$ in the second and third. Compared to the results obtained in this work, first extraction has a similar yield than in this case. Diaz et al. [38] reported consecutive extractions of exo-polygalacturonase from fermented grape pomace obtaining almost the same extraction yield up to the fourth extraction, needing at least 6 extractions in order to recover all the enzyme. Although enzyme can be recovered up to third extraction, the enzyme obtained will be much diluted already at the second extraction, which represents increasing costs in processing the extract for lesser yield. According to these data, it is recommended to perform only one extraction.

\section{Lyophilisation and activity preservation}

Enzymatic activity conservation in the lyophilized product was assessed during 115 days. The activity of the resuspended lyophilized enzyme and that of frozen samples were compared to the activity of fresh extract. The weight of remaining powder obtained was $10.881 \mathrm{~g}$ for $500 \mathrm{~mL}$ of 2-Static-BC lyophilized extract and $8.413 \mathrm{~g}$ for 5Static-BC.

Figure 3 shows the activity recovery of lyophilized and frozen extract compared to the activity of the fresh one. For the samples obtained in the 1:2 (w:v) extraction ratio, the activity recovery presented an initial drop of $20 \%$ and afterwards presented values overpassing the $100 \%$ activity recovery in the last measures. Activity losses can appear in every step from freezing to rehydration. Hédoux et al. [39] reported structural changes in protein lyophilisation after drying step, although the changes in secondary structure were reversible after rehydration. Also, other parameters of the lyophilisation process can affect the subsequent activity recovery, Passot et al. [40] reported that nucleation control by different techniques can improve activity preservation. 
In our case, values from lyophilised and unfrozen samples can be considered

479

480

481

482

483

484

485

486

487

488

489

490

491

492

493

494

495

496

497

498

499

500

501

equal, thus, there is no activity loss during the dehydratation process. The observed initial losses can be due to the freezing process and to the error associated to the cellulase determination method, as they are observed in both frozen and lyophilised samples. When comparing lyophilisation and freezing as conservation methods, lyophilisation presents some advantages which are: the concentration of the enzyme facilitating its use and the reduction of the space required for storing and the storage at not very low temperatures for its conservation. For this reason, lyophilisation should be chosen as a preservation method.

\section{Zero waste strategies}

\section{Biomethane potential}

Bio methane potential (BMP) was assayed using extracted $\mathrm{CH}$ as feedstock to evaluate the suitability of the residue after cellulase extraction for the production of biogas. Experiments were carried out during 21 days and biogas produced and methane content were measured. Although recommended ratio of inoculation according to Ponsá et al. [19] is 1:2 F:I ( $1 \mathrm{~g}$ of VS of feedstock per $2 \mathrm{~g}$ of VS of inoculum), a first experiment was carried out using different ratios F:I. As the anaerobic biodegradability of this residue had not been measured before, it was necessary to verify that a higher or lower F:I ratio was not needed in order to have an adequate biogas production. Ratios assayed were four; $1: 1 ; 1: 1.5 ; 1: 2 ; 1: 2.5$ (g of VS of feedstock: $\mathrm{g}$ of VS of Inoculum). After 21 days of incubation, biogas production was $96 \pm 10,107 \pm 7,128 \pm 10$ and $138 \pm 6 \mathrm{~mL}$ biogas $\mathrm{g}^{-1}$ VS respectively for the mentioned ratios. In view of the results obtained, ratio 1:2 (also according to Ponsá et al. [19]) was selected for future experiments. In the next 
set of biogas potential tests, fermented $\mathrm{CH}$ after and before extraction from two

503

504

505

506

507

508

509

510

511

512

513

514

515

516

517

518

519

520

521

522

523

524

525

different fermentation processes was used as anaerobic feedstock in a ratio 1:2 F:I. Tests were performed in triplicate. Biogas and methane productions are shown in Table 4. After 27 days of anaerobic digestion at $37^{\circ} \mathrm{C}$ biogas production for fermented material after extraction was $104 \pm 7 \mathrm{~mL}$ biogas $\mathrm{g}^{-1} \mathrm{VS}$ in both cases, and $124 \pm 6$ and $100 \pm 11$ $\mathrm{mL}$ biogas $\mathrm{g}^{-1} \mathrm{VS}$ for the fermented material before extraction, respectively. As for methane production, extracted samples after 27 days produced $40 \pm 8$ and $51 \pm 3 \mathrm{~mL}$ methane $\mathrm{g}^{-1} \mathrm{VS}$ and for non-previously extracted samples the methane production was $52 \pm 3$ and $54 \pm 6 \mathrm{~mL}$ methane $\mathrm{g}^{-1}$ VS respectively. Considering the standard deviation, methane production can be considered equal for all samples. As shown in Figure 4, in all cases, more than the $85 \%$ of the production was measured during the first 15 days of digestion, which indicates that the length of the process is adequate, since production remarkably decreased from that moment. Regarding biogas production, comparing this material to fresh lignocellulosic materials used as a feedstock for anaerobic digestion such as rice straw, hazelnut skin and cocoa shell, they have been reported to produce $207 \pm 22.1,223 \pm 25.1$ and $199 \pm 22.4 \mathrm{~mL} \mathrm{CH}_{4} \mathrm{~g}^{-1} \mathrm{VS}$ [41], respectively, whereas other lignocellulosic materials as ley, straw or blue mussels produced between 190 and 330 $\mathrm{mL} \mathrm{CH}_{4} \mathrm{~g}^{-1} \mathrm{VS}$ [42]. The low production of methane by coffee husk can be due to the presence of bulking agent in the mixture, which is not easily biodegradable and does not contribute to the production of biogas. Also, coffee husk is generated during the roasting process of coffee grains, which can lead to an easily biodegradable matter loss.

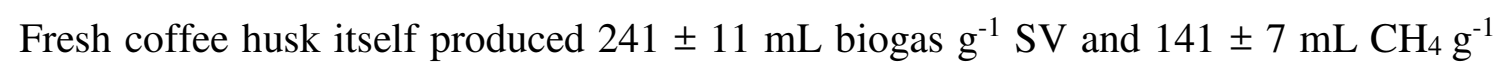
SV after 28 days of incubation, half of the amount produced by fresh lignocellulosic wastes with no previous roasting. Lee et al. [43] reported different profile in volatile 
gases during fermentation of coffees with different degree of roasting. Moreover, loss of soluble biodegradable mater also occurs during the extraction of cellulase.

\section{Composting}

Once the extraction was carried out, the remaining solid waste was stabilized in order to obtain a compost-like material adequate as agricultural amendment, closing the cycle and following a zero waste strategy.

As described previously, solid state fermentations lasted 48 hours before being stopped and extraction performed. The remaining solid after extraction was pressed manually in order to remove the maximum amount of moisture. However, the final measured moisture varied between $71 \%$ and $75 \%$ in weigh, higher than the recommended values for composting, which should be in the range of $40 \%-60 \%$ [44]. Three replicates of the composting process were performed, using $10 \mathrm{~L}$ working volume reactors. Also, a $10 \mathrm{~L}$ reactor was run containing fermented material without extraction in order to compare both materials. Oxygen consumption for the non-extracted sample was $12.5 \mathrm{mg} \mathrm{O}_{2} \mathrm{~g}^{-1} \mathrm{DM}$ day $^{-1}$, higher than that of the extracted sample of the same fermentation experiment, which was $4.3 \mathrm{mg} \mathrm{O}_{2} \mathrm{~g}^{-1} \mathrm{DM}$ day ${ }^{-1}$. Similar values were measured in the rest of the composting processes, being 4.57 and $4.43 \mathrm{mg} \mathrm{O}_{2} \mathrm{~g}^{-1} \mathrm{DM}$ day $^{-1}$. Hygenization temperatures were reached, maximum temperature measured was around $40{ }^{\circ} \mathrm{C}$. However, non-extracted material reached temperatures above $50^{\circ} \mathrm{C}$ for 24 hours approximately. Differences in biological activity of non-extracted material and extracted material can be due to the loss of soluble biodegradable material during the extraction process, since particle size of coffee husk was measured, presenting values between $1.6 \mathrm{~mm}$ and $710 \mu \mathrm{m}$. Also, biological activity could be hampered by the high moisture of the material after extraction [45]. Table 3 shows the respirometric values 
measured during the different steps of the process. It is observed that the stability of the waste was reached after 15 days of composting with values of $\mathrm{DRI}_{24}$ of $0.33 \pm 0.04 \mathrm{~g} \mathrm{O}_{2}$ $\mathrm{kg}^{-1} \mathrm{DM} \mathrm{h}^{-1}$ and $\mathrm{AT}_{4}$ of $29 \pm 5 \mathrm{~g} \mathrm{O}_{2} \mathrm{~kg}^{-1} \mathrm{DM}$. These values were very similar to the ones obtained from a mature compost sample [46]. Waste used in SSF with no extraction was also stable after 7 days of fermentation with values of $\mathrm{DRI}_{24}$ and $\mathrm{AT}_{4}$ of $0.7 \pm 0.3 \mathrm{~g} \mathrm{O}_{2}$ $\mathrm{kg}^{-1} \mathrm{DM} \mathrm{h}^{-1}$ and $59 \pm 21 \mathrm{~g} \mathrm{O}_{2} \mathrm{~kg}^{-1} \mathrm{DM}$ respectively. $\mathrm{pH}$ was measured for one replicate, presenting values between 8 and 8.5 , which are like those of final compost.

\section{Comparison of anaerobic digestion and composting}

According to coffee production companies, approximately $1 \%$ of the weight of final product ends up as coffee husk. In the case of the coffee husk supplier of this study, around $180 \mathrm{t} / \mathrm{y}$ of coffee husk are produced. According to our results, anaerobic digestion of this fermented coffee husk would represent a production of approximately $3.6 \mathrm{~kW}$ of electric power (considering the methane content of the biogas, yield of biogas conversion to electricity, etc.). Although in the case of composting no electricity is generated and there is a net consumption of energy, Zulkepli et al. [47] compared the investment required by an anaerobic digestion plant and by a composting plant for the treatment of municipal solid waste finding that capital cost was for the anaerobic digestion plant is 20 times higher than for the composting plant. In view of these facts, composting would be recommended in the present study as a low cost technology given that the production of electricity from biogas is lower than those reported for other organic wastes. However, anaerobic co-digestion could be considered if other wastes with higher biogas production are available to be treated with coffee husk fermented residues. 


\section{Conclusion}

578 Different aspects of the downstream stage in the production of cellulase through solid 579 state fermentation of coffee husk were assessed in this work. Extraction parameters as 580 solid:solvent ratio, agitation mode and type of solvent seem to have low influence in the 581 total activity recovery. Buffering effect of citrate solution does not present any 582 advantage over distillate water on enzyme solubility. Contact between solid and solvent appears to be adequate independently of the agitation provided. Although maximum activity recovery was $108 \pm 30 \%$ performing the extraction under 1:5 w:v ratio, static mode and distilled water as solvent, statistically equal result was obtained using 1:2 w:v ratio.

Activity loss after lyophilisation is not observed, as values oscillate around $100 \%$ recovery during the first 50 days of lyophilized material storage. For the aerobic stabilization of the extracted material, water can hamper the process, thus, a previous drying step is recommended. At the end of the stabilization process a compost-like

591 product is obtained, which can be used as organic amendment. Biogas production

592 resulted in low values compared with other agricultural wastes. Therefore, anaerobic digestion of the residue is recommended in co-digestion with higher anaerobically biodegradable residues.

In summary, a detailed process to optimize the production of cellulase from lignocellulosic wastes is presented, considering the overall process from SSF to a final

597 lyophilized product. The strategies to manage the spent material after extraction are also presented for a zero waste process. 
600

601

602

603

604

605

606

607

608

609

610

611

612

613

614

615

616

617

618

619

620

621

622

623

624

625

626

627

628

629

630

631

632

633

\section{References}

1. British Petroleum plc.: http://www.bp.com/es_es/spain/prensa/notas-de-prensa /2016/bp-statistical-review world-energy-2016.html Accessed 10 July 2017

2. Kuhad, R.C., Gupta, R., Singh, A.: Microbial Cellulases and Their Industrial Applications. Enzyme Research DOI 10.4061/2011/280696 (2011)

3. Cherian, E., Dharmendirakumar, M., Baskar. G.: Immobilization of Cellulase onto $\mathrm{MnO}_{2}$ Nanoparticles for Bioethanol Production by Enhanced Hydrolysis of Agricultural Waste. Chinese J Catal. 36 (8), 1223-1229 (2015)

4. Idris, A.S.O., Pandey, A.; Rao, S.S., Sukumaran, R.K.: Cellulase Production through Solid-State Tray Fermentation, and Its Use for Bioethanol from Sorghum Stover. Bioresource Technol. 242, 265-271 (2017)

5. Li, Y.H., Zhang, X.Y., Xiong, L., Mehmood, M.A., Zhao, X.Q., Bai, F.W.: On-Site Cellulase Production and Efficient Saccharification of Corn Stover Employing cbh2 Overexpressing Trichoderma Reesei with Novel Induction System. Bioresource Technol. 238, 643-649 (2017)

6. Oke, A.M., Suffian, M., Annuar, M., Simarani, K.: Mixed Lignocellulosic Biomass Degradation and Utilization for Bacterial Cellulase Production. Waste Biomass Valori. 8(3), 893-903 (2017)

7. Saini, A., Aggarwal, N.K., Yadav, A.: Cost-Effective Cellulase Production Using Parthenium Hysterophorus Biomass as an Unconventional Lignocellulosic Substrate. 3 Biotech. 7(1), 1-11(2017)

8. Sun, H.Y., Li, J.H., Zhao, P.J., Peng, M.: Banana Peel: A Novel Substrate for Cellulase Production under Solid-State Fermentation. Afr J Biotechnol. 10(77), 17887-17890 (2011)

9. Dhillon, G.S., Kaur, S., Brar, S.K., Verma, M.: Potential of Apple Pomace as a Solid Substrate for Fungal Cellulase and Hemicellulase Bioproduction through Solid-State Fermentation. Ind Crop Prod. 38, 6-13 (2012)

10. Yoon, L.W., Ang, T.N., Ngoh, G.C., Chua, A.S.M.: Fungal Solid-State Fermentation and Various Methods of Enhancement in Cellulase Production. Biomass Bioenerg. 67, 319-38 (2014)

11. Trivedi, N., Reddy, C.R.K., Radulovich, R., Jha, B.: Solid State Fermentation (SSF)-Derived Cellulase for Saccharification of the Green Seaweed Ulva for Bioethanol Production. Algal Res. 9, 48-54 (2015) 
12. Cerda, A., Gea, T., Vargas-Garcia, M.C., Sanchez, A.: Towards a Competitive Solid State Fermentation: Cellulases Production from Coffee Husk by Sequential Batch Operation and Role of Microbial Diversity. Sci Total Environ. 589, 56-65 (2017)

13. Maulini-Duran, C., Puyuelo, B., Artola, A., Font, X., Sanchez, A., Gea, T.: VOC Emissions from the Composting of the Organic Fraction of Municipal Solid Waste Using Standard and Advanced Aeration Strategies. J Chem Technol Biot. 89(4), 579$586(2014)$

14. Puyuelo, B., Gea, T., Sanchez, A.: A New Control Strategy for the Composting Process Based on the Oxygen Uptake Rate. Chem Eng J. 165(1), 161-169 (2010)

15. Pirota, R.D.P.B., Miotto, L.S., Delabona, P.S., Farinas, C.S.: Improving the Extraction Conditions of Endoglucanase Produced by Aspergillus Niger under SolidState Fermentation. Braz J Chem Eng. 30(1), 117-23 (2013)

16. Chandra, M.S., Viswanath, B., Reddy, B.R.: Optimization of extraction of $\beta$ endoglucanase from the fermented bran of Aspergillus Niger. Indian J Microbiol. 50(1), 122-126 (2010)

17. Farinas, C.S., Loyo, M.M., Baraldo Junior, A., Tardioli, P.W., Bertucci Neto, V., Couri, S.: Finding stable cellulase and xylanase: evaluation of the synergistic effect of pH and temperatura. New Biotechnol. 27 (6), 810-815 (2010)

18. German Federal Ministry for the Environment, Nature Conservation and Nuclear Safety, Ordinance on environmentally compatible storage of waste from human settlements and on biological waste treatment facilities of 20 February (2001) URL:http://www.bmu.de/files/pdfs/allgemein/application/pdf/ablagerungsverordnun g.pdf Accessed 25 July 2017

19. Ponsá, S., Gea, T., Sánchez, A.: Anaerobic co-digestion of the organic fraction of municipal solid waste with several pure organic co-substrates. Biosyst Eng. 108(4), 352-360 (2011)

20. Sayara, T., Sarrà, M., Sánchez, A.: Effects of Compost Stability and Contaminant Concentration on the Bioremediation of PAHs-Contaminated Soil through Composting', J Hazard Mater. 179 (1-3), 999-1006 (2010)

21. Ghose, T.K.: Measurement of Cellulase Activities. Pure Appl Chem. 59(2), 257268 (1987)

22. Adani, F., Gigliotti, G., Valentini, F., Laraia, R.: Respiration Index Determination: A Comparative Study of Different Methods. Compost Sci Util. 11(2), 144-151 (2003) 
23. Pognani, M., Barrena, R., Font, X., Adani, F., Scaglia, B., Sanchez, A.: Evolution of Organic Matter in a Full-Scale Composting Plant for the Treatment of Sewage Sludge and Biowaste by Respiration Techniques and Pyrolysis-GC/MS. Bioresource Technol. 102(6), 4536-4543 (2011)

24. Gea, T., Barrena, R., Artola, A.,Sanchez, A.: Monitoring the Biological Activity of the Composting Process: Oxygen Uptake Rate (OUR), Respirometric Index (RI), and Respiratory Quotient (RQ). Biotechnol Bioeng. 88(4), 520-527 (2004)

25. Almeira, N., Komilis, D., Barrena, R., Gea, T., Sánchez, A.: The importance of aeration mode and flowrate in the determination of the biological activity and stability of organic wastes by respiration indices. Bioresource Technol. 196, 256-262 (2015)

26. The U.S. Department of Agriculture and The U.S. Composting Council (2001) Test Methods for the Examination of Composting and Compost, Edaphos International, Houston

27. Van Soest, P., Robertson, J., Lewis, B.: Methods for dietary fiber, neutral detergent fiber, and non-starch polysaccharides in relation to animal nutrition. J Dairy Sci. 74(10), 3583-3597 (1991)

28. Miller, G.: Use of Dinitrosalicylic Acid Reagent for Determination of Reducing Sugar. Anal Chem. 31(3), 426-428 (1959)

29. Ruggieri, L., Gea, T., Artola, A., Sanchez, A.: Air Filled Porosity Measurements by Air Pycnometry in the Composting Process: A Review and a Correlation Analysis. Bioresource Technol. 100(10), 2655-66 (2009)

30. Krishna, C.: Solid-State Fermentation Systems: An Overview. Crit Rev Biotechnol. 25(1-2), 1-30 (2005)

31. Alburquerque, J.A., McCartney, D., Yu, S., Brown, L., Leonard, J.J.: Air space in composting research: A literature review. Compost Sci Util. 16(3), 159-170 (2008)

32. Sarkar, N., Ghosh, S.K., Bannerjee, S., Aikat, K.: Bioethanol Production from Agricultural Wastes: An Overview. Renew Energ. 37, 19-27 (2012)

33. Jimenez-Penalver, P., Gea, T., Sanchez, A., Font, X.: Production of Sophorolipids from Winterization Oil Cake by Solid-State Fermentation: Optimization, Monitoring and Effect of Mixing. Biochem Eng J. 115, 93-100 (2016)

34. Rezaei, F., Joh, L.D., Kashima, H., Reddy, A.P., VanderGheynst, J.S.: Selection of Conditions for Cellulase and Xylanase Extraction from Switchgrass Colonized by Acidothermus Cellulolyticus. Appl Biochem Biotech. 164(6), 793-803 (2011) 
35. Singh, S.A., Ramakrishna, M., Appu Rao, A.G.: Optimisation of Downstream Processing Parameters for the Recovery of Pectinase from the Fermented Bran of Aspergillus Carbonarius. Process Biochem. 35(3-4), 411-17 (1999)

36. Bera, M.B., Panesar, P.S., Panesar, R., Singh, B.: Application of Reverse Micelle Extraction Process for Amylase Recovery Using Response Surface Methodology. Bioproc Biosyst Eng. 31(4), 379-84 (2008)

37. Shata, H.M.A.: Extraction of Milk-Clotting Enzyme Produced by Solid State Fermentation of Aspergillus Oryzae. Pol J Microbiol. 54(3), 241-47 (2005)

38. Díaz, A.B., Caro, I., de Ory, I., Blandino, A.: Evaluation of the conditions for the extraction of hydrolitic enzymes obtained by solid state fermentation from grape pomace. Enzyme Microb Tech. 41, 302-306 (2007)

39. Hédoux, A., Paccou, L., Achir, S., Guinet, Y.: In Situ Monitoring of Proteins during Lyophilization Using Micro-Raman Spectroscopy: A Description of Structural Changes Induced by Dehydration. J Pharm Sci. 101(7), 2316-26 (2012)

40. Passot, S.,Trelea, I.C., Marin, M., Galan, M., Morris, G.J., Fonseca, F.: Effect of Controlled Ice Nucleation on Primary Drying Stage and Protein Recovery in Vials Cooled in a Modified Freeze-Dryer. J Biomech Eng. 131(7), 74511 (2009)

41. Mancini, G., Papirio, S., Lens, P.N.L., Esposito, G.: Effect of $\mathrm{N}$ Methylmorpholine- N -Oxide Pretreatment on Biogas Production from Rice Straw, Cocoa Shell, and Hazelnut Skin. Environ Eng Sci. 33(11), 843-50 (2016)

42. Ammenberg, J., Feiz, R.: Assessment of Feedstocks for Biogas Production, Part II: Results for Strategic Decision Making. Resour Conserv Recy. 122, 388-404 (2017) 43. Lee, L.W., Tay, G.Y., Cheong, M.W., Curran, P., Yu, B., Liu, S.Q.: Modulation of the Volatile and Non-Volatile Profiles of Coffee Fermented with Yarrowia Lipolytica : II. Roasted Coffee. Lebensm-Wiss Technol. 80, 32-42 (2017)

44. Kim, E., Lee, D.H., Won, S., Ahn, H.: Evaluation of Optimum Moisture Content for Composting of Beef Manure and Bedding Material Mixtures Using Oxygen Uptake Measurement. Asian Austral J Anim. 29(5), 753-58 (2016)

45. Richard, T.L., Hamelers, H.V.M., Veeken, A., Silva, T.: Moisture Relationships in Composting Processes. Compost Sci Util. 10(4), 286-302 (2002)

46. Komilis, D., Kanellos, D.: A modified dynamic respiration test to assess compost stability: Effect of sample size and air flowrate. Bioresource Technol. 117, 300-309 (2012) 

Analysis of composting and anaerobic digestion in a community: A review. Chem Eng Trans. 56, 1777-1782 (2017) 


\section{Tables}

Table 1. Characterization of wastes used as substrates in SSF.

\begin{tabular}{|c|c|c|c|}
\hline Parameter & Coffee Husk & Compost & Mixture** \\
\hline $\mathrm{pH}$ & $6.4 \pm 0.1$ & $7.6 \pm 0.5$ & $6.7 \pm 0.4$ \\
\hline $\mathrm{CE}\left(\mathrm{mS} \mathrm{cm}^{-1}\right)$ & n.m. & $6.3 \pm 0.2$ & n.m. \\
\hline Moisture $(\%, w b)$ & $60.2 \pm 0.6$ & $35 \pm 1$ & $61 \pm 1$ \\
\hline Dry mater $(\%, w b)$ & $40.1 \pm 0.4$ & $64 \pm 1$ & $39 \pm 1$ \\
\hline Organic matter* $(\%, \mathrm{db})$ & $90.21 \pm 0.01$ & n.m. & 90 \\
\hline Total C* $(\%, d b)$ & 80.1 & n.m. & n.m. \\
\hline Total $N^{*}(\%, d b)$ & 3.5 & n.m. & n.m. \\
\hline $\mathrm{C} / \mathrm{N}$ ratio & $22.9 \pm 0.1$ & n.m. & n.m. \\
\hline Bulk density* $\left(\mathrm{g} \mathrm{L}^{-1}\right)$ & 238.1 & n.m. & 358 \\
\hline Air filled porosity* (\%) & 78.9 & n.m. & 77.2 \\
\hline Reducing sugars $(\%, \mathrm{db})$ & $0.65 \pm 0.01$ & n.m. & n.m. \\
\hline Glucose $(\%, \mathrm{db})$ & $0.02 \pm 0.01$ & n.m. & n.m. \\
\hline Cellulose $(\%, \mathrm{db})$ & $25.7 \pm 0.2$ & $10 \pm 1$ & $26 \pm 3$ \\
\hline Hemicellulose $(\%, \mathrm{db})$ & $14.6 \pm 0.1$ & $10.2 \pm 0.1$ & $13.25 \pm 0.07$ \\
\hline $\operatorname{Lignin}(\%, \mathrm{db})$ & $17.6 \pm 0.5$ & $14 \pm 1$ & $21.1 \pm 1.0$ \\
\hline
\end{tabular}

wb: wet basis. db: dry basis; n.a.: not available. AFP: Air filled porosity (v/v, percentage in volume). Values are the average of independent experiments and its standard deviation. $(*)$ s.d. $<6 \%$ n.m.: not measured. (**) Mixture of compost and coffee husk at 1:1 weight ratio and bulking agent in a volume ratio 1:1 
Table 2. Summary of extraction experiments, 30 min extraction time.

\begin{tabular}{|c|c|c|c|}
\hline Extraction method & pH & Conductivity $\left(\mathrm{mS} \mathrm{cm}^{-1}\right)$ & Activity recovery (\%) \\
\hline 2-Static-DW ${ }^{\text {a, b, e, g }}$ & $9.0 \pm 0.2$ & $3.6 \pm 0.2$ & $84 \pm 22$ \\
\hline 2-Agitated-DW c, d, e, g & $9.0 \pm 0.2$ & $3.8 \pm 0.3$ & $56 \pm 14$ \\
\hline 2-Static-BC ${ }^{b, c, f, g}$ & $6.1 \pm 0.5$ & $7.8 \pm 0.5$ & $58 \pm 6$ \\
\hline 2-Agitated-BC ${ }^{c, d, e, f, g}$ & $6.2 \pm 0.9$ & $7.9 \pm 0.6$ & $56 \pm 12$ \\
\hline 3-Static-DW a & $9.12 \pm 0.05$ & $2.6 \pm 0.2$ & $95 \pm 13$ \\
\hline 3-Agitated-DW a, b, d & $9.11 \pm 0.07$ & $2.8 \pm 0.1$ & $84 \pm 15$ \\
\hline 3-Static-BC ${ }^{c, d, e}$ & $5.6 \pm 0.2$ & $7.2 \pm 0.5$ & $61 \pm 3$ \\
\hline 3-Agitated-BC ${ }^{b, c, g}$ & $5.9 \pm 0.4$ & $7.6 \pm 0.5$ & $69 \pm 12$ \\
\hline 5-Static-DW a & $9.21 \pm 0.09$ & $1.5 \pm 0.1$ & $108 \pm 30$ \\
\hline 5-Agitated-DW ${ }^{\mathrm{g}}$ & $9.1 \pm 0.1$ & $1.9 \pm 0.1$ & $50 \pm 7$ \\
\hline 5-Static-BC ${ }^{\text {a, b }}$ & $5.2 \pm 0.1$ & $6.9 \pm 0.5$ & $83 \pm 18$ \\
\hline 5-Agitated-BC ${ }^{\text {a }}$ & $5.4 \pm 0.1$ & $7.2 \pm 0.5$ & $103 \pm 17$ \\
\hline
\end{tabular}

BC: Buffer citrate mono hydrate $\mathrm{pH}$ 4.8; DW: distilled water; 2: extraction ratio 1:2 (w:v), 3: extraction ratio 1:3 (w:v), 5: extraction ratio 1:5 (w:v).

Subscript indicates the groups of extractions that are considered equal according to $t-$ student test.

Values are the average of independent experiments. 
Table 3. Result of respirometric assay. Final SSF values are initial composting values.

\begin{tabular}{lcc} 
& $\mathbf{A T}_{\mathbf{4}}\left(\mathbf{O}_{\mathbf{2}} \mathbf{~ g}^{-\mathbf{1}} \mathbf{D M}\right)$ & $\mathbf{D R I}_{\mathbf{2 4}}\left(\mathbf{O}_{\mathbf{2}} \mathbf{~ g}^{-\mathbf{1}} \mathbf{D M} \mathbf{~ h}^{\mathbf{- 1}}\right)$ \\
\hline Fresh material & $86 \pm 23$ & $1.6 \pm 0.2$ \\
48 hours of SSF - Before extraction & $86 \pm 17$ & $1.3 \pm 0.3$ \\
7 days of SSF - Before extraction & $59 \pm 21$ & $0.7 \pm 0.3$ \\
48 hours of SSF - After extraction & $47 \pm 7$ & $0.70 \pm 0.06$ \\
Stabilized (previous extraction) & $29 \pm 5$ & $0.33 \pm 0.04$ \\
Stabilized (no previous extraction) & $20.0 \pm 0.7$ & $0.29 \pm 0.01$
\end{tabular}

All values are the average of independent experiments. 
Table 4. Biogas production of coffee husk anaerobic digestion. For the materials before and after extraction, two independent fermentations were evaluated for biogas and methane production.

\begin{tabular}{|c|c|c|c|c|c|}
\hline & \multirow[t]{2}{*}{ Fresh material } & \multicolumn{2}{|c|}{ Before extraction } & \multicolumn{2}{|c|}{ After extraction } \\
\hline & & $\begin{array}{c}\text { Fermentation } \\
1 \\
\end{array}$ & $\begin{array}{c}\text { Fermentation } \\
2 \\
\end{array}$ & $\begin{array}{c}\text { Fermentation } \\
1 \\
\end{array}$ & $\begin{array}{c}\text { Fermentation } \\
2 \\
\end{array}$ \\
\hline $\begin{array}{l}\text { Biogas production } \\
\left(\mathrm{mL} \mathrm{g}^{-1} \mathrm{VS}\right)\end{array}$ & $241 \pm 11$ & $124 \pm 6$ & $100 \pm 11$ & $104 \pm 7$ & $104 \pm 7$ \\
\hline $\begin{array}{l}\text { Methane production } \\
\left(\mathrm{mL} \mathrm{g}^{-1} \mathrm{VS}\right)\end{array}$ & $141 \pm 7$ & $52 \pm 3$ & $54 \pm 6$ & $40 \pm 8$ & $51 \pm 3$ \\
\hline
\end{tabular}

All values are the average of triplicate measurements. 


\section{Figure captions}

Fig. 1 Temperature (solid line) and OUR $1 \mathrm{~h}$ (dotted line) profiles of $\mathrm{CH}$ solid state fermentation

Fig. 2 Percentage of activity recovery of three consecutive extractions over the same solid. Three independent experiments are showed

Fig. 3 Percentage of activity recovery of: lyophilised samples of $\mathrm{CH}$ extracted in Static mode, using $\mathrm{BC}$ and ratio 1:2 (w:v) (circles), 1:5 (w:v) (diamonds) and unfrozen samples of $\mathrm{CH}$ extracted in Static mode, using BC and ratio 1:2 (w:v) (triangles), 1:5 (w:v) (squares)

Fig. 4 Biogas production from anaerobic digestion of fresh coffee husk (squares), fermented coffee husk before extraction (triangles) and fermented coffee husk after extraction (circles). For materials before and after extraction, two independent fermentations were evaluated. 
Fig. 1

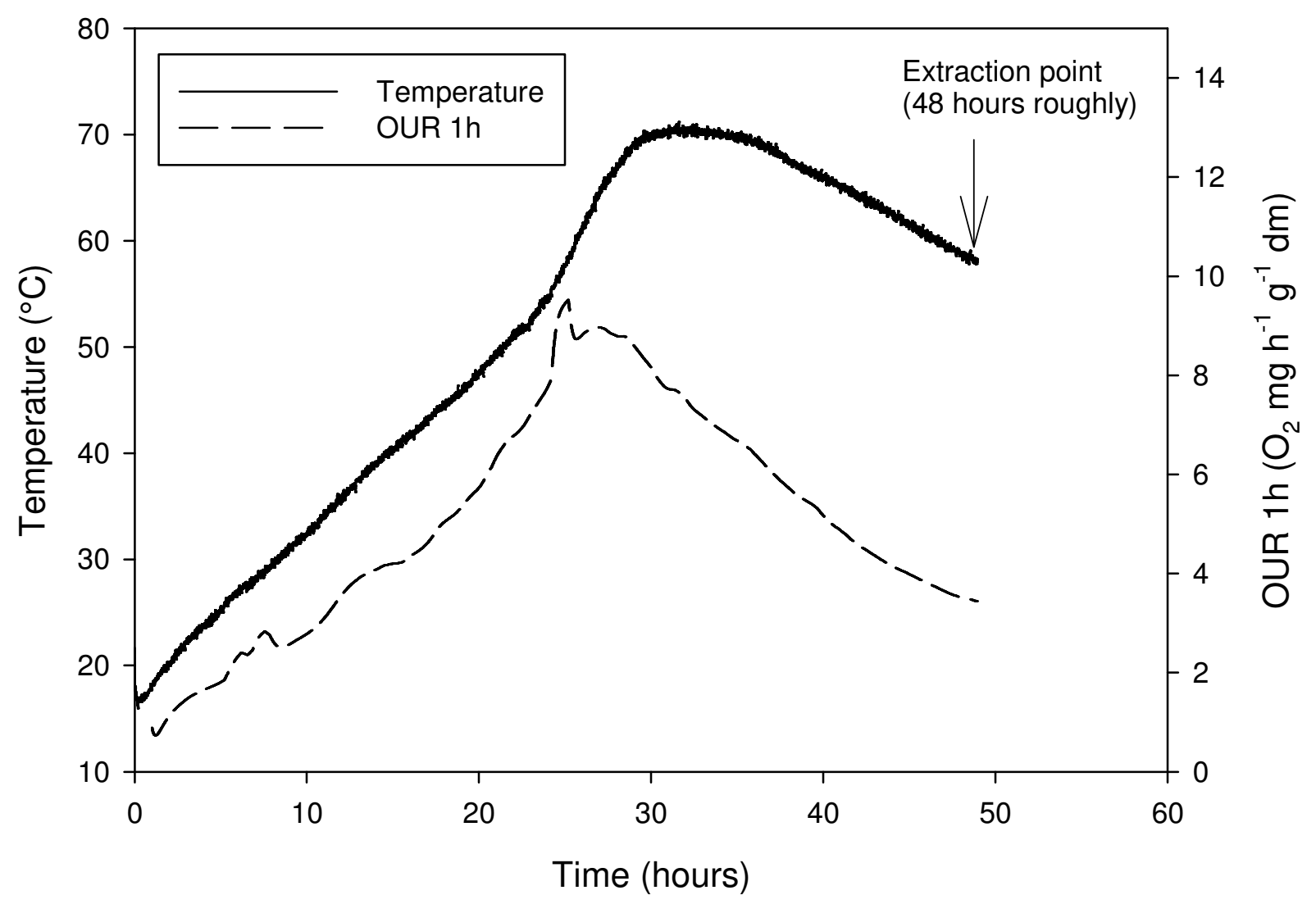


Fig. 2

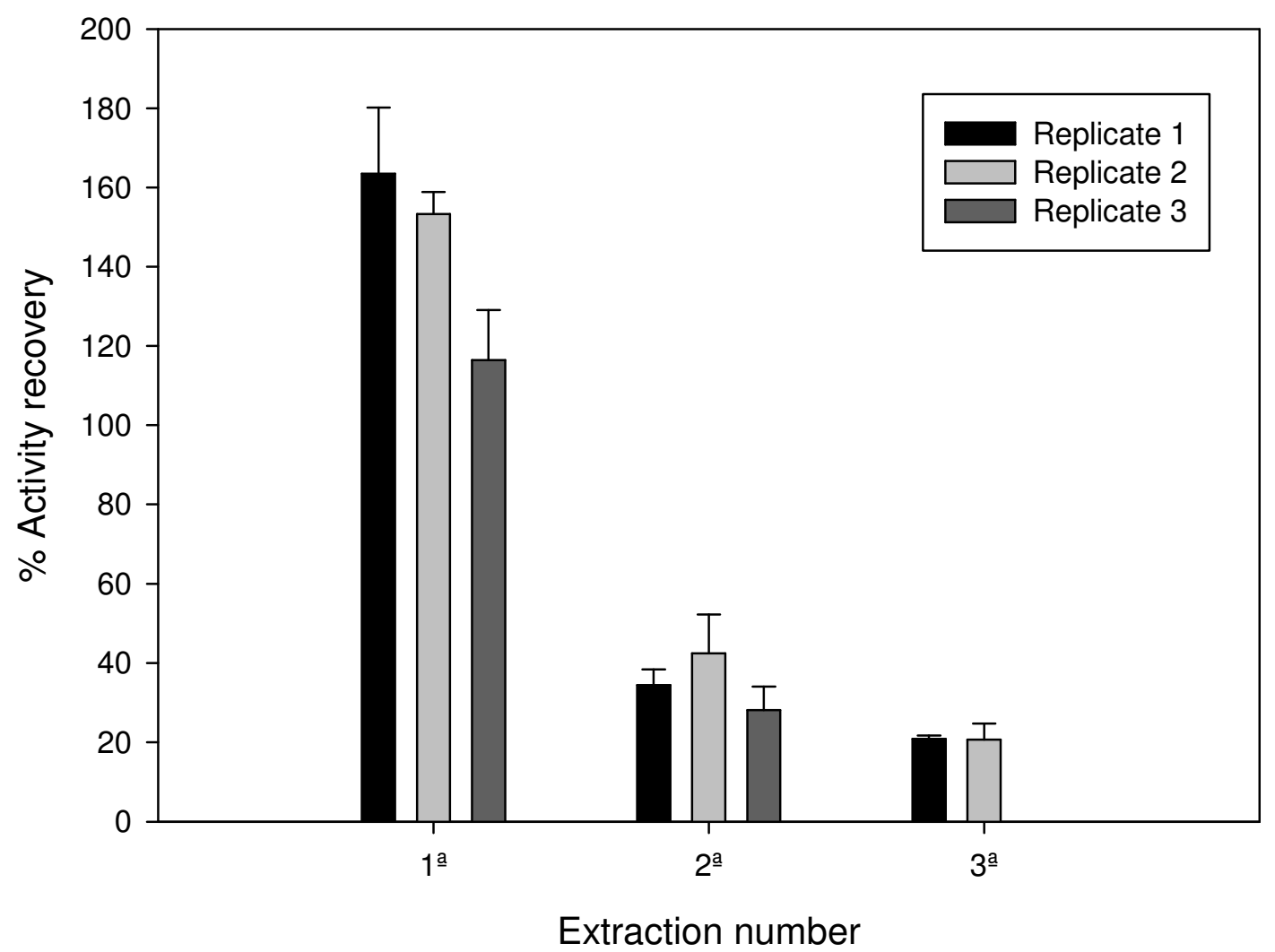


Fig. 3

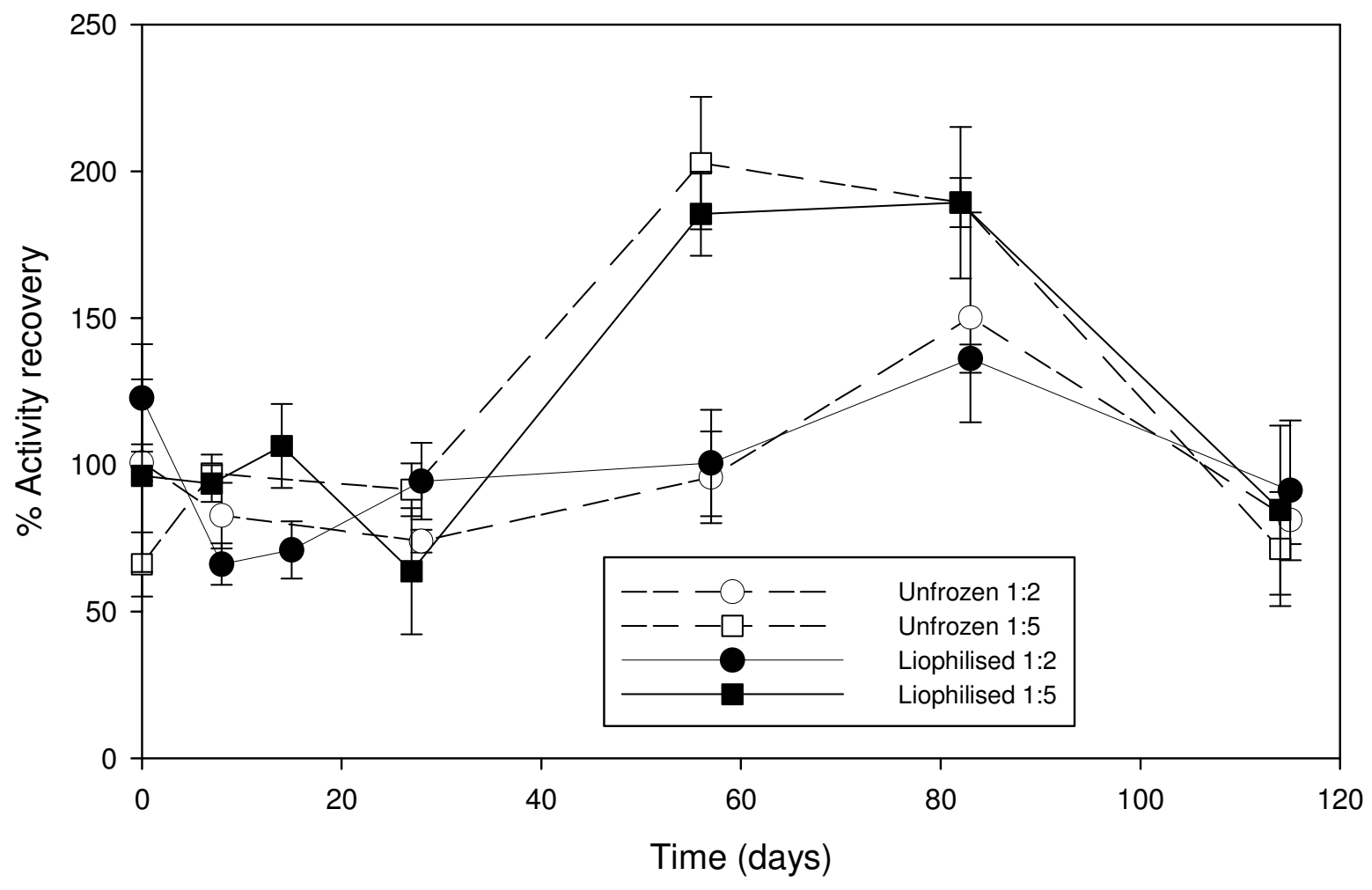


Fig. 4

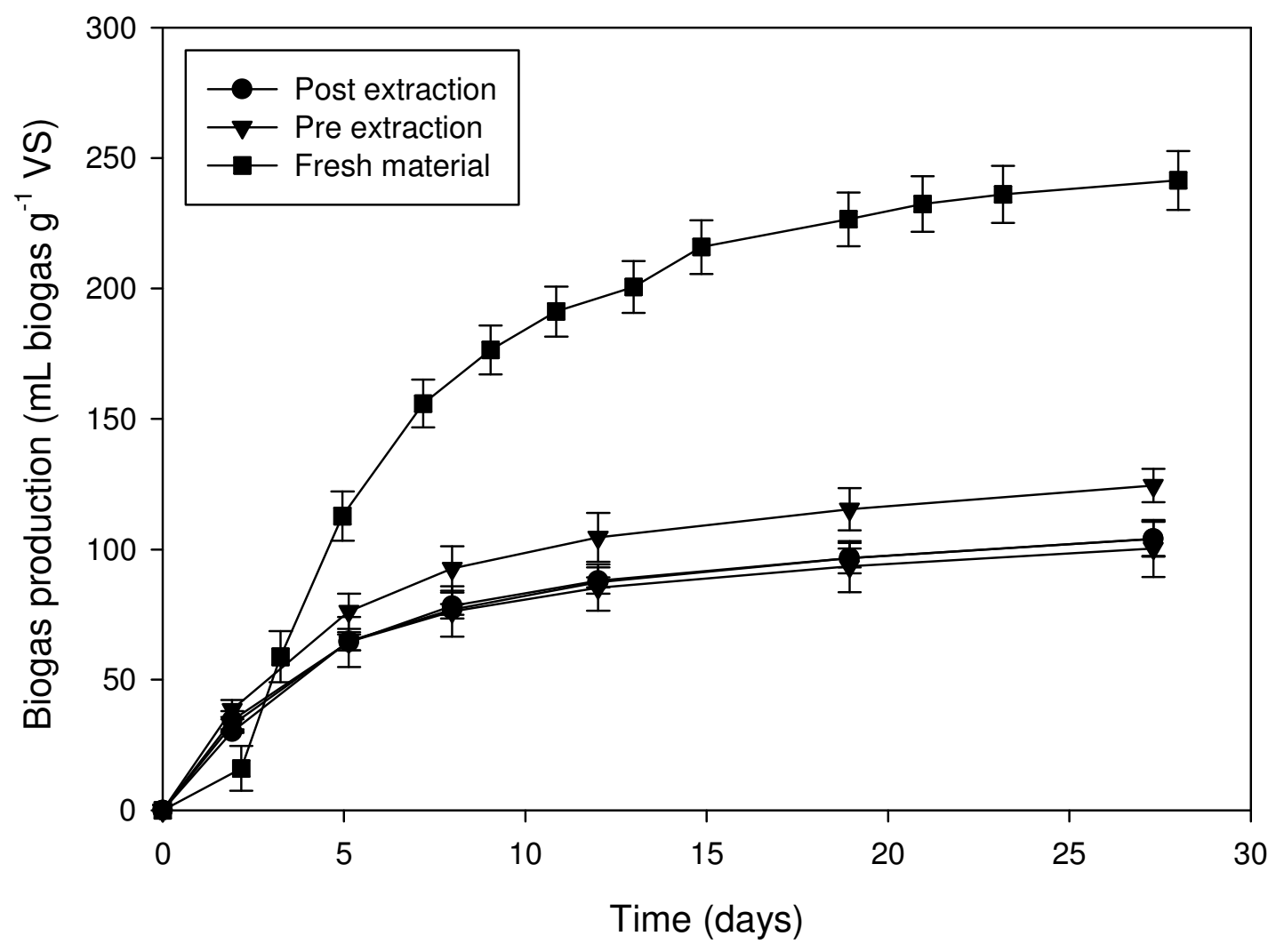

